\title{
Histidine residue at position 226 is critical for iodide uptake activity of human sodium/iodide symporter
}

\author{
Shih-Lu Wu, Tin-Yun Ho ${ }^{1,2}$, Ji-An Liang ${ }^{3}$ and Chien-Yun Hsiang ${ }^{4}$ \\ Department of Biochemistry, China Medical University, 91 Hsueh-Shih Road, Taichung 40402, Taiwan, ROC \\ ${ }^{1}$ Graduate Institute of Chinese Medical Science, China Medical University, Taichung 40402, Taiwan, ROC \\ ${ }^{2}$ Nuclear Medicine and PET Center and ${ }^{3}$ Department of Radiation Therapy and Oncology, China Medical University Hospital, Taichung 40447, Taiwan, ROC \\ ${ }^{4}$ Department of Microbiology, China Medical University, 91 Hsueh-Shih Road, Taichung 40402, Taiwan, ROC \\ (Correspondence should be addressed to C-Y Hsiang; Email: cyhsiang@mail.cmu.edu.tw)
}

\begin{abstract}
The sodium/iodide symporter (SLC5A5; also known as NIS), a transmembrane glycoprotein principally in the thyroid gland, is responsible for the accumulation of iodide necessary for thyroid hormones. Our previous study indicated that a novel exon 6 deletion (residues 233-280) in SLC5A5 loses the iodide uptake activity. Herein we characterized the role of His-226 in iodide transport of SLC5A5. His-226, a highly conserved extracellular residue among SLC5A5 homologs, was replaced with alanine, aspartic acid, glutamic acid, or lysine. All the SLC5A5 mutants were expressed normally in
\end{abstract}

the cells and targeted correctly to the plasma membrane. However, all of the mutants displayed severe defects in iodide uptake, suggesting that His-226 was critical for iodide uptake. Kinetic analysis further showed that mutation at His-226 led to a dramatic decrease in $V_{\max }$. These findings suggested that the decreased levels of iodide uptake activity of SLC5A5 mutants resulted from lower catalytic rates. In conclusion, our data first identified the involvement of extracellular charged amino acid residue in the iodide uptake ability of SLC5A5.

Journal of Endocrinology (2008) 199, 213-219

\section{Introduction}

The sodium/iodide symporter (SLC5A5; also known as NIS) is a transmembrane glycoprotein that mediates the active transport of iodide into the follicular thyroid cells and other tissues (Dohan \& Carrasco 2003). In the thyroid tissue, iodide uptake is the first step in thyroid hormone synthesis. The ability of SLC5A5 to accumulate iodide in the thyroid gland has long been used for the diagnostic scintigraphic imaging or the radioiodide therapy of the thyroid. The mutation of SLC5A5 has also been correlated with the congenital iodide transport defect (ITD), which leads to hypothyroidism in patients. The SLC5A5 mutations detected in patients with ITD have provided the significant structural information about the symporter. So far, 12 ITD-causing SLC5A5 mutations have been identified: V59E, G93R, Q267E, C272X, G395R, T354P, frame-shift 515X, Y531X, G543E, $\triangle$ M143-Q323, $\triangle$ A439-P443, and G543E. T354P, G395R, Q267E, and G543E have been thoroughly characterized at the molecular level (Levy et al. 1998, Dohan et al. 2002, 2004). Although they are defective in iodide uptake, T354P, G395R, and Q267E SLC5A5 proteins are correctly targeted to the plasma membrane, while G543E mutant impairs the maturation and trafficking of SLC5A5 (De La Vieja et al. 2004). Since all the ITD-causing SLC5A5 mutations are located at the transmembrane or intracellular regions, they cannot account for how the SLC5A5 mediates the iodide transport from the extracellular space into the intracellular region.

In this study, we tried to identify the critical amino acid residues that mediated the iodide uptake in SLC5A5. By sitedirected mutagenesis and kinetic analysis, we found that mutation at His-226 caused a severe defect in iodide uptake but not in the expression and plasma membrane targeting. These findings suggested that His-226, a highly conserved residue in the extracellular region, was involved in the iodide transport of SLC5A5.

\section{Materials and Methods}

\section{Cloning}

Human SLC5A5 cDNA was cloned as described previously (Petrich et al. 2002). Briefly, two overlapping cDNA fragments representing either the $5^{\prime}$-half or the $3^{\prime}$-half of the complete SLC5A5 coding region were amplified and inserted into pBluescript II KS (-) vector (Invitrogen) to create pBKS-SLC5A5-5' and pBKS-SLC5A5-3' plasmids respectively. A full-length SLC5A5 clone was then constructed by in-frame fusion of both halves using a unique $B g l$ II side in the overlap of the fragments. The full-length 
SLC5A5 clone was subcloned into pcDNA3.1 expression vector (Invitrogen) to create pcDNA3.1-SLC5A5 plasmid DNA. Plasmid DNA created in this study was confirmed as an in-frame construction by sequencing and prepared with the Qiagen plasmid midi kit (Qiagen).

\section{Site-directed mutagenesis}

Site-directed mutagenesis was performed as described previously (Ho et al. 2000). Briefly, uracil-containing single-stranded DNA (ssDNA) was prepared by transforming pBKS-SLC5A5-5' into Escherichia coli (E.coli) CJ236 strain, which lost its deoxyuridine triphosphate nucleotidohydrolase and uracil glycosylase activities. Uracil-containing ssDNA was annealed with $5^{\prime}$-kinase primer and the second-strand DNA was synthesized in the presence of thyroxine (T4 DNA ligase, T4 DNA polymerase, and deoxyribonucleotides. The dsDNA was then transformed into E. coli NM522 strain to destroy the uracil-containing strand by uracil glycosylase activity and to allow the mutated strand to be amplified. The primers H226A (5'-CAGAACGCGTCCCGGATCAACCTCATGG-3'), H226D (5'-CCAGAACGATTCCCGGATCAACCTCATGG-3'), H226E (5'-CCAGAACGAATCCCGGATCAACCTCATGG-3'), and H226K (5'-TCACGCTTGCGCAGAACAAATCCCGGATCAACCTCATGG-3') were designed to displace the histidine residues with alanine, aspartic acid, glutamic acid, and lysine residues, respectively, and to create $M l u$ I, Tfi I, Tfi I, Mst I sites, respectively, at the same time. The full-length SLC5A5 mutant clones were then constructed as described previously.

\section{Cell culture and transient transfection}

Human hepatoblastoma HepG2 cell line was maintained in Dulbecco's modified Eagle's medium (DMEM; Life Technologies) supplemented with $10 \%$ (v/v) fetal bovine serum (HyClone, Logan, UT, USA). HepG2 cells were transiently transfected with pcDNA3.1-SLC5A5 wild-type, pcDNA3.1SLC5A5 mutant, pcDNA3.1, or pcDNA3.1/lacZ DNAs (Invitrogen) by SuperFect transfection reagent (Qiagen Inc.) and the treated cells were then kept in a humidified incubator at $37^{\circ} \mathrm{C}$ with $5 \% \mathrm{CO}_{2}$ for $24 \mathrm{~h}$.

\section{Total RNA extraction and reverse transcription-PCR (RT-PCR)}

RNA extraction was performed as described previously (Hsiang et al. 2007). RNA integrity was electrophoretically verified by both the ethidium bromide staining and the absorption ratio (OD260/OD280>1.95). Total RNA (1 $\mu \mathrm{g})$ was reverse transcribed with $200 \mathrm{U}$ SuperScript III (Invitrogen) and oligo $(\mathrm{dT})_{15}$ primer. RT mixtures were subjected to PCR to measure the mRNAs of SLC5A5 and $\beta$-actin. PCR amplification was performed with Taq polymerase (Promega) for 20 cycles at $94^{\circ} \mathrm{C}$ for $45 \mathrm{~s}, 50{ }^{\circ} \mathrm{C}$ for $45 \mathrm{~s}$, and $72{ }^{\circ} \mathrm{C}$ for $1 \mathrm{~min}$. PCR primers for SLC5A5 were as follows: sense,
$5^{\prime}$-CTCCTCCCTGCTAACGACTC-3'; antisense, $5^{\prime}$-CGACCACCATCATGTCCAAC- $3^{\prime}$; PCR primers for $\beta$-actin were as follows: sense, $5^{\prime}$-TGACGGGGTCACCCACACTGTGCCCATCTA-3'; antisense, 5'-CTAGAAGCATTGCGGTGGACGATGGAGGG-3'. The intensities of bands on the gels were calculated by Gel-Pro Analyzer (Media Cybernetics Inc., Silver Spring, MD, USA).

\section{Immunofluorescence and confocal microscopy}

The HepG2 cells were seeded in 24-well plates, which contained sterilized cover slips, incubated at $37^{\circ} \mathrm{C}$ for 2 days, and transiently transfected with DNAs. One day later, the cells were washed twice with PBS (137 mM NaCl, 1.4 mM KH $2 \mathrm{PO}_{4}, 4.3 \mathrm{mM}$ $\mathrm{Na}_{2} \mathrm{HPO}_{4}$ and $2 \cdot 7 \mathrm{mM} \mathrm{KCl}, \mathrm{pH} 7 \cdot 2$ ), fixed with $3 \cdot 7 \%(\mathrm{v} / \mathrm{v})$ PBS-buffered formaldehyde for $30 \mathrm{~min}$ at room temperature, and washed thrice with PBS. Cover slips were then incubated with mouse anti-SLC5A5 monoclonal antibody (Lab Vision, Fremont, CA, USA) overnight at $4{ }^{\circ} \mathrm{C}$, washed thrice with PBS, and incubated with fluorescein-conjugated goat anti-mouse $\operatorname{IgG}$ antibody (Jackson ImmunoResearch, West Grove, PA, USA) for $2 \mathrm{~h}$ at $37^{\circ} \mathrm{C}$. Cover slips were mounted and examined using a confocal microscope (Leica, Wetzlar, Germany), with an excitation wavelength of $488 \mathrm{~nm}$. Anti-SLC5A5 monoclonal antibody was against amino acids 625-643, mapping to the carboxyl terminus of human SLC5A5.

\section{Iodide uptake and reporter assays}

For steady-state analysis, the cells were incubated for $1 \mathrm{~h}$ with $10 \cdot 2 \mu \mathrm{Ci} / \mathrm{ml}$ carrier-free $\mathrm{Na}^{125} \mathrm{I}$ in $1 \mathrm{ml} \mathrm{DMEM}$ at $37^{\circ} \mathrm{C}$. For the inhibition of SLC5A5-mediated uptake, $\mathrm{NaClO}_{4}$ (final concentration, $30 \mu \mathrm{M})$ was included in parallel incubations. After a $1 \mathrm{~h}$ incubation, the medium was completely removed and washed twice with $2 \mathrm{ml}$ ice-cold PBS. After washing, the cells were lysed with $350 \mu \mathrm{l}$ Triton lysis buffer $(50 \mathrm{mM}$ Tris$\mathrm{HCl}, \mathrm{pH} 7 \cdot 8,1 \%$ (v/v) Triton X-100, $1 \mathrm{mM}$ dithiothreitol). Radioactivities of lysates were determined by a Cobra II autogamma counter (Packard BioScience, Dreieich, Germany). $\beta$-Galactosidase activities of cell lysates were analyzed by mixing cell lysates with $\mathrm{O}$-nitrophenyl-beta-D-galactopyranoside. After a $30 \mathrm{~min}$ incubation at $37^{\circ} \mathrm{C}$, the absorbance values of the mixtures were measured at $420 \mathrm{~nm}$.

For kinetic analysis, the cells were incubated for $4 \mathrm{~min}$ with $6 \cdot 25,12 \cdot 5,25,50,100,200,400,800$, and $1600 \mu \mathrm{M} \mathrm{NaI}$, and uptake reactions were determined as described previously. Data were processed using the equation: $v=\left(V_{\max } \times\right.$ $[\mathrm{I}]) /\left(K_{\mathrm{m}}+[\mathrm{I}]\right)+0 \cdot 0156 \times[\mathrm{I}]+2 \cdot 4588$. The terms $0 \cdot 0156 \times$ $[\mathrm{I}]+2 \cdot 4588$ correspond to the background adjusted by least squares to the data obtained with non-transfected cells.

\section{Molecular modeling}

The sequence of SLC5A5 was analyzed using the Structure Prediction Meta Server (http://bioinfo.pl; Bujnicki et al. 2001). The structure of E. coli glycerol-3-phosphate 
(G3P) transporter (protein data bank code 1PW4) was chosen as the modeling template. Theoretical modeling of the protein structure was carried out using PyMOL Release 0.98 (http://www.pymol.org).

\section{Statistical analysis}

Data were presented as mean \pm s.D. Student's $t$-test was used for comparisons between two experiments. $P<0 \cdot 05$ was considered statistically significant.

\section{Results}

His-226 was the highly conserved residue located on the extracellular region of SLC5A5

Multiple alignments and secondary structures of SLC5A5 homologs were analyzed to identify the highly conserved extracellular histidine residue of SLC5A5. The current SLC5A5 secondary structure model depicts SLC5A5 as a protein with 13 transmembrane segments (Spitzweg \& Morris 2004). The multiple alignments of SLC5A5 amino acid sequences from human, pig, mouse, and rat showed that one histidine residue located at 226 was highly conserved among SLC5A5 analogs (Fig. 1). Additionally, His-226 was located on the extracellular region of SLC5A5. Therefore, His-226 was replaced with non-charged residue (alanine) or charged residues (aspartic acid, glutamic acid, and lysine), and the mutants were characterized by iodide uptake assay.

SLC5A5 wild-type and mutants displayed the similar transcriptional levels and plasma membrane targeting patterns

HepG2 cells were transiently transfected with SLC5A5 wildtype or mutant DNAs. After $24 \mathrm{~h}$, the RNA level and plasma membrane targeting of SLC5A5 were evaluated by RT-PCR and immunofluorescence staining respectively. Figure $2 \mathrm{~A}$ shows that the SLC5A5 mRNA level was consistent in the cells expressing either wild-type or mutant SLC5A5. Figure 2B shows that, by using mouse monoclonal antibody against

\begin{abstract}
Human MEAVETGERPTFGAWDYGVFALMLLVSTGIGLWVGLARGGQRSAEDFFTGGRRLAALPVGLSLSASFMSAVQVLGVPSEAYRYGLKFLWM 120 Mouse MEGAEAGARATFGPWDYGVFATMLLVSTGIGLWVGLARGGQRSADDFFTGGRQLAAVPVGLSLAASFMSAVQVLGVPAEAARYGLKFLWM 120 Rat MEGAEAGARATFGAWDYGVFATMLLVSTGIGLWVGLARGGQRSADDFFTGGRQLAAVPVGLSLAASFMSAVQVLGVPAEAARYGLKFLWM 120 Pig MATVEGGARATFGAWDYGVFALMLLVSTGIGLWVGLARGGQRSAEDFFTGGRRLTAVPVGLSLSASFMSAVQVLGVPAEAYRYGLKFLWM 120

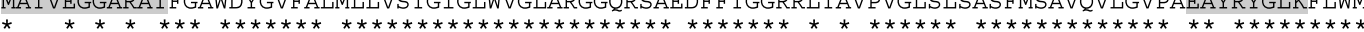

Human CLGQLLNSVLTALLFMPVFYRLGLTSTYEYLEMRFSRAVRLCGTLQYIVATMLYTGIVIYAPALILNQVTGLDIWASLLSTGIICTFYTA 180 Mouse CVGQLLNSLLTALLFLPIFYRLGLTSTYQYLELRFSRAVRLCGTLQYLVATMLYTGIVIYAPALILNQVTGLDIWASLLSTGIICTLYTT 180 Rat CAGQLLNSLITAFLFIPIFYRLGLTSTYQYLELRFSRAVRLCGTLQYLVATMLYTGIVIYAPAIILNOVTGLDIWASLLSTGIICTLYTT 180 CLGQLLNSLLTALLFLPVFYRLGLTSTYQYLELRFSRAVRLCGTLQYLVATMLYTGVVIYAPALILNQVTGLDIWASLLSTGI ICTFYTT 180

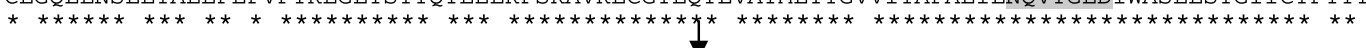

Pig VGGMKAVVWTDVFQVVVMLSGFWVVLARGVMLVGGPROVLTLAQNHSRINLMDFNPDPRSRYTFWTFVVGGTLVWLSMYGVNOAOVQRYV 270 VGGMKAVVWTDVFQVVVMLVGFWVILARGVMLMGGPWNVLSLAQNHSRINLMDFDPDPRSRYTFWTFVVGGSLVWLSMYGVNQAQVQRYV 270 VGGMKAVVWTDVFQVVVMLVGFWVILARGVILLGGPRNVLSLAQNHSRINLMDFDPDPRSRYTFWTFIVGGTLVWLSMYGVNQAQVQRYV 270 VGGMKAVIWTDVFQVLVMLTGFWVVLARGTVLVGGPGRVLELAKNHSRINLMDFDLDPRRRYTFWTFVVGGTLVWLSMYGVNQAQVQRYV 270

Rat

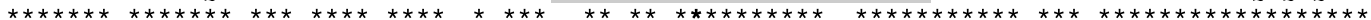

Human ACRTEKQAKLALLINQVGLFLIVSSAACCGIVMFVFYTDCDPLLLGRISAPDQYMPLLVLDIFEDLPGVPGLFLACAYSGTLSTASTSIN 360 Mouse ACHTERKAKLALLVNOLGLFLIVASAACCGIVMFVYYKDCDPLLTGRIAAPDOYMPLLVLDIFEDLPGVPGLFLACAYSGTLSTASTSIN 360 ACHTEGKAKLALLVNQLGLFLIVASAACCGIVMFVYYKDCDPLLTGRISAPDQYMPLLVLDIFEDLPGVPGLFLACAYSGTLSTASTSIN 360

Pig ACRTEKQAKLALLINQVGLFLIVSSAAACGIVMFALYVDCDPLLAGHISAPDQYMPLLVLDIFEDLPGVPGLFLACAYSGTLSTASTSIN 360

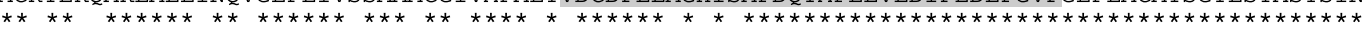

Human

Mouse

AMAAVTVEDLIKPRLRSLAPRKLVIISKGLSLIYGSACLTVAALSSLLGGGVLQGSFTVMGVISGPLLGAFILGMFLPACNTPGVLAGLG 450 AMAAVTVEDLIKPRMPSLAPRKLVFISKGLSFIYGSTCLTVAALSSLLGGGVLQGSFTVMGVISGPLLGAFTLGMLLPACNTPGVLSGLT 450 AMAAVTVEDL I KPRMPGLAPRKLVFISKGLSFIYGSACLTVAALSSLLGGGVLQGSFTVMGVISGPLLGAFTLGMLLPACNTPGVLSGLA 450 AMAAVTVEDLIKPRLPNLAPRRLVI ISKGLSLIYGSACLTVAALSSLLGGGVLQGSFTVMGVISGPLLGAFVLGMFLPSCNTSGVLSGLA 450

Pig

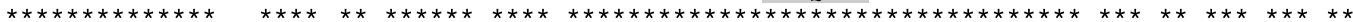

Human

Mouse

AGLALSLWVALGATLYPPSEQTMRVLPSSAARCVALSVNASGLLDPALLPANDSSRAPSSGMDASRPALADSFYAISYLYYGALGTLTTV 540 AGLAVSLWVAVGATLYPPGEQTMGVLPTSAAGCT- - -NASVLPSP - PGAANTSRGIPSSGMDSGRPAFADTFYAVSYLYYGALGTLTTM 535 AGLAVSLWVAVGATLYPPGEQTMGVLPTSAAGCT----NDSVLLGP-PGATNASNGIPSSGMDTGRPALADTFYAISYLYYGALGTLTTM 535

Rat

Pig

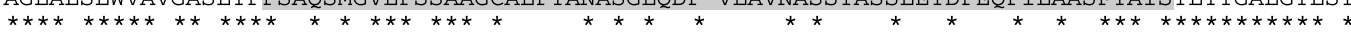

Human LCGALISCLTGPTKRSTLAPGLLWWDLARQTASVAPKEEVAILDDNLVK-GPEELPTGNKKPPGFLPTNEDRLFFLGQKELEGAGSWTPC 629 Mouse LCGALISYLTGPTKRSSLGPGLLWWDLARQTASVAPKEDTTTLEDSLVK-GPEDIPAATKKPPGFRPEAETHPLYLG-- - - - - - - . 611 Rat LCGALISYLTGPTKRSSLGPGLLWWDLARQTASVAPKEDTATLEESLVK-GPEDIPAVTKKPPGLKPGAETHPLYLG- - - - - - - - - - 611 Pig LCGALISCLTGPTKRSALGPGLLWWDLTRQTASVAPKEEVAALDDSLMKQGAEELPLAIKKPPDFLSTNEDHLLFLGQKEVNGASSKTPG 629

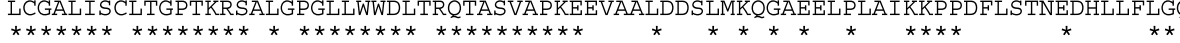

Human VGHDGGDQQETNL 643

Mouse $\quad$ - HD - .-.VETNL 618

Rat --HD-----VETNL 618

Pig SEHDKGHDLRETDL 643

Figure 1 Multiple alignments of SLC5A5 homologs. Amino acid sequences of SLC5A5 from mouse, rat, and pig were aligned with those of human by CLUSTALW. Residues that are identical in all SLC5A5 homologs are indicated by asterisks. Residues that are located on the extracellular regions are highlighted in gray. The conserved histidine residue is indicated by an arrow. 


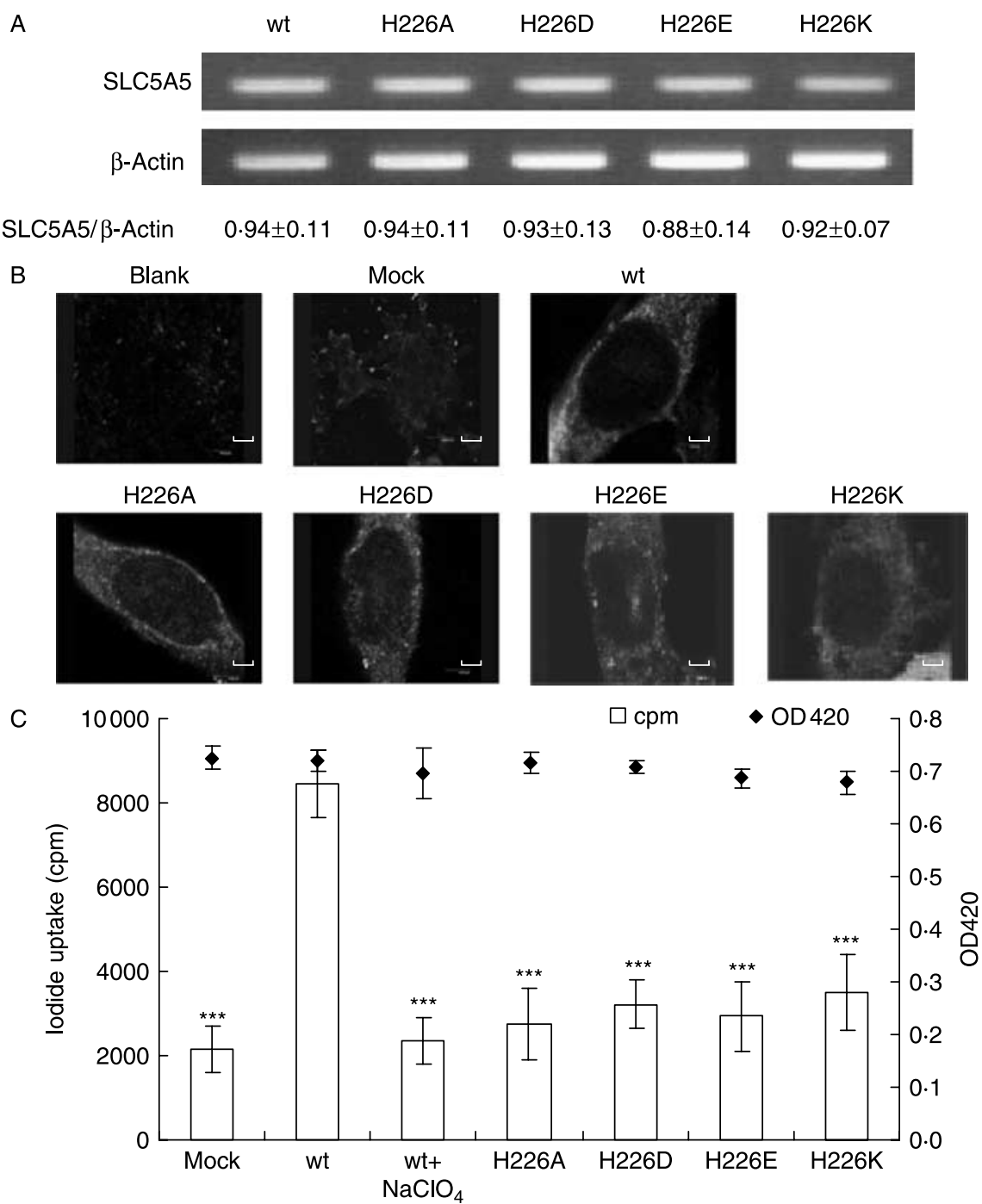

Figure 2 Expression, plasma membrane targeting, and iodide uptake abilities of SLC5A5 mutants. (A) RT-PCR. HepG2 cells were cultured in $25 \mathrm{~cm}^{2}$ flasks and transfected with wild-type (wt), H226A, H226D, H226E, or H226K plasmid DNAs. Total RNAs were extracted and $1 \mu \mathrm{g}$ total RNA was reverse transcribed. The resulting CDNAs were then amplified by PCR. The PCR products were resolved in agarose gels and visualized with ethidium bromide. The ratio between SLC5A5 and $\beta$-actin expressions is presented at the bottom. Values are mean \pm s.D. error of triplicate assays. (B) Immunofluorescence. HepG2 cells were cultured on glass cover slips and transfected without DNA (blank) or with pcDNA3.1 (mock), wt, H226A, H226D, H226E, or H226K plasmid DNAs for 2 days. The cells were then treated with anti-SLC5A5 antibody, stained with fluorescenceconjugated secondary antibody, and evaluated under a confocal microscope. Magnification, $400 \times$. Bars, $4 \mu \mathrm{m}$. Similar results were obtained in three different experiments. (C) HepG2 cells were transfected with pcDNA3.1/lacZ and pcDNA3.1 (Mock), wt, H226A, H226D, H226E, or H226K DNAs. After $24 \mathrm{~h}$, iodide uptake and $\beta$-galactosidase abilities were evaluated. Values are mean \pm s.D. error of triplicate assays. ${ }^{* * *} P<0 \cdot 001$, compared with wild-type.

the C-terminus of SLC5A5, mutated SLC5A5-expressing cells displayed the similar plasma membrane-associated immunofluorescence staining pattern with wild-type SLC5A5-expressing cells. These findings indicated that SLC5A5 mutants were not defective in transcription and plasma membrane targeting.

\section{His-226 mutants were defective in iodide uptake}

The iodide uptake activities of His-226 mutants were analyzed by steady-state iodide uptake assay. The transcription efficiency was monitored by $\beta$-galactosidase activity. As shown in Fig. 2C, wild-type SLC5A5-expressing cells 
exhibited a significant iodide uptake activity. Perchlorate treatment led to a marked decrease in iodide uptake, suggesting the specificity of iodide uptake assay. Replacement of His-226 with Ala, Asp, Glu, or Lys showed a drastically reduced iodide uptake activity. Because the $\beta$-galactosidase activities were consistent in wild-type and mutated SLC5A5expressing cells, the dramatic reductions of iodide uptake in His-226 mutants resulted from the amino acid substitution but not from the transfection variation.

\section{His-226 mutants displayed lower $\mathrm{V}_{\max }$ values than wild-type}

We further analyzed the kinetic properties of iodide uptake in HepG2 cells expressing wild-type or mutated SLC5A5. Initial rates were assessed by measuring iodide accumulation at 4 min time points over a range of $6 \cdot 25,12 \cdot 5,25,50,100,200$, 400, 800, and $1600 \mu \mathrm{M}$ NaI. Typical Michaelis-Menten kinetic was used to determine the $V_{\max }$ and $K_{\mathrm{m}}$ values of SLC5A5. The $V_{\max }$ and $K_{\mathrm{m}}$ values of wild-type SLC5A5 derived from experiments were $6 \cdot 34 \pm 1 \cdot 34$ c.p.m. per 4 min and $67 \cdot 85 \pm 27 \cdot 98 \mu \mathrm{M}$ respectively (Fig. 3; Table 1 ). No significant variation in the $K_{\mathrm{m}}$ was observed among the cells expressing the mutant proteins with respect to wild-type SLC5A5. By contrast, a dramatic decrease in $V_{\max }$ was observed when histidine residue at position 226 was substituted by alanine. Replacement with Asp or Lys also led to a markedly decrease in $V_{\max }$. Because H226A, H226D, $\mathrm{H} 226 \mathrm{E}$, and H226K mutants were normally expressed and properly targeted to the plasma membrane, the kinetic

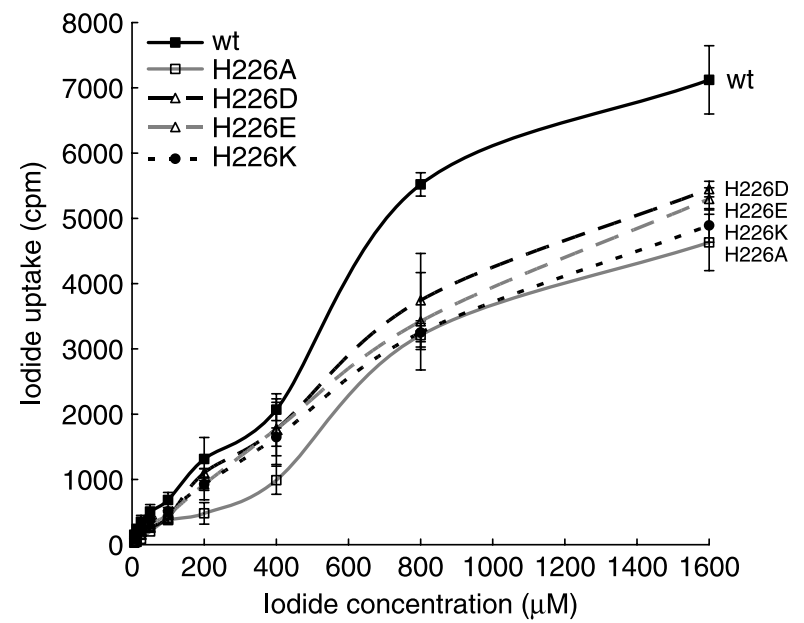

Figure 3 Kinetic analysis of SLC5A5 mutants. HepG2 cells were transfected with wild-type (wt), H226A, H226D, H226E, or H226K plasmid DNAs. After $24 \mathrm{~h}$, initial rates (4 min time points) of iodide uptake were determined at the indicated concentrations of iodide. Calculated curves were generated using the equation $v=\left(V_{\max } \times\right.$ $[I]) /\left(K_{\mathrm{m}}+[\mathrm{I}]\right)+0 \cdot 0156 \times[\mathrm{I}]+2 \cdot 4588$. The terms $0 \cdot 0156 \times[\mathrm{I}]+$ $2 \cdot 4588$ correspond to background adjusted by least squares to the data obtained with non-transfected cells. Values are mean \pm s.D. error of triplicate experiments.
Table 1 Kinetic analysis of SLC5A5 wild-type and mutants

\begin{tabular}{|c|c|c|}
\hline & $V_{\max }^{a}$ & $K_{m}^{a}$ \\
\hline Wt & $6 \cdot 34 \pm 1 \cdot 34$ & $67 \cdot 85 \pm 27 \cdot 98$ \\
\hline $\mathrm{H} 226 \mathrm{~A}$ & $2 \cdot 62 \pm 0.03^{\neq}$ & $93 \cdot 16 \pm 19 \cdot 83$ \\
\hline $\mathrm{H} 226 \mathrm{D}$ & $4 \cdot 83 \pm 0.24^{*}$ & $119 \cdot 60 \pm 14 \cdot 17$ \\
\hline $\mathrm{H} 226 \mathrm{E}$ & $4.67 \pm 1.69$ & $83 \cdot 20 \pm 60 \cdot 65$ \\
\hline $\mathrm{H} 226 \mathrm{~K}$ & $4 \cdot 27 \pm 0 \cdot 81^{+}$ & $76 \cdot 28 \pm 53 \cdot 88$ \\
\hline
\end{tabular}

${ }^{*} P<0 \cdot 05,{ }^{\dagger} P<0 \cdot 01,{ }^{\ddagger} P<0 \cdot 001$, compared with wild-type.

${ }^{a}$ Values are mean \pm s.D. error of triplicate experiments.

analysis suggested that these mutants cause a reduction in the iodide transport rate.

\section{Discussion}

The SLC5A5, a member of sodium/glucose cotransporter family (SLC5), is an integral transmembrane glycoprotein (Wright \& Turk 2004). Mutations on the amino acids residues, which are located on the transmembrane and intracytoplasmic regions, have been identified and characterized. For examples, T354P, Q267E, and G543E SLC5A5 mutants from ITD patients show severe defects on the iodide uptake (De la Vieja et al. 2005). Site-directed mutagenesis on the highly conserved serine and threonine residues in the transmembrane segment of SLC5A5 shows that these amino acid residues are important for transport activity (De La Vieja et al. 2007). Mutations on the phosphorylation sites (Ser-43, Thr-49, and Thr-577) of SLC5A5 also show that the SLC5A5 function can be modulated by phosphorylation (Vadysirisack et al. 2007). Although the critical roles of amino acid residues in the transmembrane and intracellular regions have been characterized, these studies have raised the question of whether the amino acid residues in the extracellular region of SLC5A5 are important for iodide uptake ability.

In our previous study, we demonstrated that the deletion of exon 6, encoding for the residues 233-280 in the extracellular and transmembrane regions of SLC5A5, loses the iodide uptake activity (Liang et al. 2005). Other studies on apical sodium-dependent bile acid transporter (SLC10A2) also showed that two positive ligand-binding sites are located on the extracellular region (Zhang et al. 2004, Banerjee et al. 2005). Therefore, which amino acid residues in the extracellular region of SLC5A5 are critical for iodide uptake is the issue we would like to address in this study.

Histidine residues play key roles in a number of membrane proteins involved in sodium transport. For example, mutation of histidine residues in system $\mathrm{A}$ and $\mathrm{N}$ amino acid transporters, the $\mathrm{Na}^{+}$-dependent transporters of SLAC38 gene family, produces a reduced transport phenotype (Baird et al. 2006). Histidine residue has also been shown to be important in the E. coli $\mathrm{Na}^{+}$/ $\mathrm{H}^{+}$exchanger NhaA and Arabidopsis cation/ $\mathrm{H}^{+}$exchanger (Wiebe et al. 2001, Shigaki et al. 2005). Replacement of histidine with alanine at position 106 of $\mathrm{Na}^{+} /$dicarboxylate 
co-transporter NaDC-1 also exhibits a decrease in succinate transport (Pajor et al. 1998). Multiple alignment of SLC5A5 homologs revealed that only one histidine residue, located on the extracellular region, was highly conserved. Replacement of His-226 with neutral or charged amino acid residues displayed severe defects in iodide uptake. Kinetic analysis also showed that $V_{\max }$ value was markedly decreased in the cells expressing SLC5A5 mutant proteins. These findings first reported that charged histidine residue in the extracellular region of SLC5A5 was critical for iodide transport activity.

How did His-226 affect the iodide transport of SLC5A5? To answer this question, we created the three-dimensional structure of SLC5A5 using E. coli G3P transporter as the reference protein (Fig. 4A). Although SLC5A5 exhibits a $12 \cdot 4 \%$ amino acid identity $(21 \cdot 3 \%$ similarity) with E. coli G3P transporter (Supplementary Figure 1, see Supplementary data in the online of version of the Journal of Endocrinology at http://joe.endocrinology-journals.org/content/vol199/ issue2/), SLC5A5 shares the similar biological function with G3P transporter. For example, both proteins use a solute gradient to drive the translocation of substrates (Lemieux et al. 2004). Moreover, both proteins have 12-13 transmembrane $\boldsymbol{\alpha}$-helices (Huang et al. 2003). The recognizable homology suggests that G3P transporter as the template for the modeling of SLC5A5 is reasonable. The predicted SLC5A5 structure showed that SLC5A5 was wider at the extracellular side and constricted at the intracellular end. Thirteen transmembrane $\boldsymbol{\alpha}$-helices form a channel, representing the substrate translocation pore. The side chains of T354, G395, and Q267, which are known to be critical for iodide transport, extrude forward to the interior of the channel (Fig. 4B). It
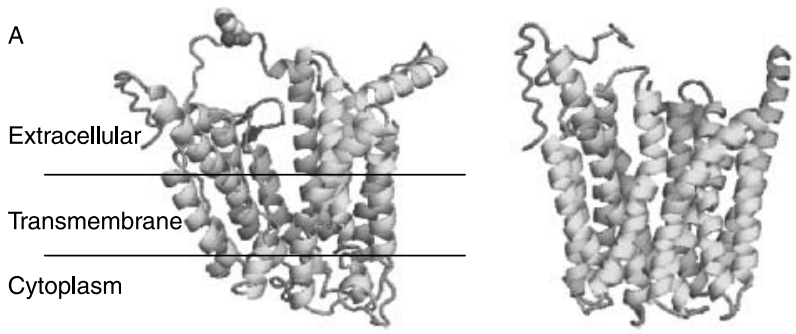

B

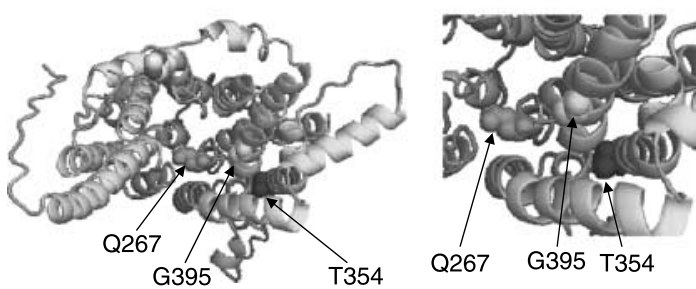

Figure 4 Structure modeling of SLC5A5. (A) The three-dimensional structure of SLC5A5 (left panel) was modeled using E. coli G3P (PDB code 1PW4; right panel) as the reference protein. His-226 is represented by spheres. Extracellular, transmembrane, and cytoplasmic regions are indicated. (B) The structure rotated $90^{\circ}$ along $x$-axis relative to (A). Q267, G395, and T354 residues are indicated by arrows. Closeup view of these residues are shown in the right panel. may explain why these amino acid residues are important in iodide transport activity. It also emphasized the accuracy of SLC5A5 structure modeling. It is interesting to find that His226 was located on the extracellular loop and the side chain of His-226 was forward to the center of the pore. We proposed that His-226 may be saved as the hinge, which attracted the iodide ion and pitched it into the interior of the cells. Replacement of His-226 with neutral residue, negativecharged residues, or positive-charged amino acids with long carbon chains may fail to attract the iodide ion, resulting in the loss of iodide transport ability (Supplementary Figure 2, see Supplementary data in the online of version of the Journal of Endocrinology at http://joe.endocrinology-journals.org/ content/vol199/issue2/). Although Ser-227 is situated nearby the His-226, Ser-27 is a non-charged amino acid residue that cannot attract the iodide ions. It may explain why Ser-227 had no effect on the $K_{\mathrm{m}}$ or $V_{\max }$ of SLC5A5 in the previous study (Vadysirisack et al. 2007).

In conclusion, although several studies have characterized the roles of critical neutral amino acid residues in the transmembrane and intracellular regions of SLC5A5, our findings are the first to demonstrate that the charged amino acid residue, histidine, in the extracellular region of SLC5A5 plays an important role in iodide transport.

\section{Declaration of interest}

The authors declare that there is no conflict of interest that would prejudice its impartiality.

\section{Funding}

This work was supported by grants from National Research Program for Genomic Medicine, National Science and Technology Program for Agricultural Biotechnology, National Science Council, Committee on Chinese Medicine and Pharmacy (CCMP96-RD-201, CCMP97-RD201), and China Medical University, Taiwan.

\section{Acknowledgements}

We thank Mr Wen-Yi Chang for his technical assistance.

\section{References}

Baird FE, Pinilla-Tenas JJ, Ogilvie WL, Ganapathy V, Hundal HS \& Taylor PM 2006 Evidence for allosteric regulation of $\mathrm{pH}$-sensitive system A (SNAT2) and system N (SNAT5) amino acid transporter activity involving a conserved histidine residue. Biochemical Journal 397 369-375.

Banerjee A, Ray A, Chang C \& Swaan PW 2005 Site-directed mutagenesis and use of bile acid-MTS conjugates to probe the role of cysteines in the human apical sodium-dependent bile acid transporter (SLC10A2). Biochemistry 44 8908-8917.

Bujnicki JM, Elofsson A, Fischer D \& Rychlewski L 2001 Structure prediction meta server. Bioinformatics 17 750-751.

Dohan O \& Carrasco N 2003 Advances in $\mathrm{Na}(+) / \mathrm{I}(-)$ symporter (NIS) research in the thyroid and beyond. Molecular and Cellular Endocrinology 213 59-70. 
Dohan O, Gavrielides MV, Ginter C, Amzel LM \& Carrasco N 2002 $\mathrm{Na}(+) / \mathrm{I}(-)$ symporter activity requires a small and uncharged amino acid residue at position 395. Molecular Endocrinology 16 1893-1902.

Ho TY, Wu SL, Hsiang CH, Chang TJ \& Hsiang CY 2000 Identification of a DNA-binding domain and an active-site residue of pseudorabies virus DNase. Biochemical Journal 346 441-445.

Hsiang CY, Wu SL, Chen CJ, Lo HY, Li CC, Chiang SY, Wu HC \& Ho TY 2007 Acetaldehyde induces matrix metalloproteinase-9 gene expression via nuclear factor- $\mathrm{\kappa B}$ and activator protein 1 signaling pathways in human hepatocellular carcinoma cells: association with the invasive potential. Toxicology Letters 171 78-86.

Huang Y, Lemieux MJ, Song J, Auer M \& Wang DN 2003 Structure and mechanism of the glycerol-3-phosphate transporter from Escherichia coli. Science 301 616-620.

Lemieux MJ, Huang Y \& Wang DN 2004 Glycerol-3-phosphate transporter of Escherichia coli: structure, function and regulation. Research in Microbiology 155 623-629.

Levy O, De la Vieja A, Ginter CS, Riedel C, Dai G \& Carrasco N 1998 N-linked glycosylation of the thyroid $\mathrm{Na}^{+} / \mathrm{I}^{-}$symporter (NIS). Implications for its secondary structure model. Journal of Biological Chemistry 273 22657-22663.

Liang JA, Chen CP, Huang SJ, Ho TY, Hsiang CY, Ding HJ \& Wu SL 2005 A novel loss-of-function deletion in sodium/iodide symporter gene in follicular thyroid adenoma. Cancer Letters 230 65-71.

Pajor AM, Sun N \& Valmonte HG 1998 Mutational analysis of histidine residues in the rabbit $\mathrm{Na}^{+} /$dicarboxylate co-transporter $\mathrm{NaDC}-1$. Biochemical Journal 331 257-264.

Petrich T, Helmeke HJ, Meyer GJ, Knapp WH \& Potter E 2002 Establishment of radioactive astatine and iodine uptake in cancer cell lines expressing the human sodium/iodide symporter. European Journal of Nuclear Medicine and Molecular Imaging 29 842-854.

Shigaki T, Barkla BJ, Miranda-Vergara MC, Zhao J, Pantoja O \& Hirschi KD 2005 Identification of a crucial histidine involved in metal transport activity in the Arabidopsis cation/H+ exchanger CAX1. Journal of Biological Chemistry 280 30136-30142.
Spitzweg C \& Morris JC 2004 Gene therapy for thyroid cancer: current status and future prospects. Thyroid 14 424-434.

Vadysirisack DD, Chen ES, Zhang Z, Tsai MD, Chang GD \& Jhiang SM 2007 Identification of in vivo phosphorylation sites and their functional significance in the sodium iodide symporter. Journal of Biological Chemistry 282 36820-36828.

De La Vieja A, Ginter CS \& Carrasco N 2004 The Q267E mutation in the sodium/iodide symporter (NIS) causes congenital iodide transport defect (ITD) by decreasing the NIS turnover number. Journal of Cell Science 117 677-687.

De La Vieja A, Ginter CS \& Carrasco N 2005 Molecular analysis of a congenital iodide transport defect: G543E impairs maturation and trafficking of the $\mathrm{Na}^{+} / \mathrm{I}^{-}$symporter. Molecular Endocrinology 19 2847-2858.

De La Vieja A, Reed MD, Ginter CS \& Carrasco N 2007 Amino acid residues in transmembrane segment IX of the $\mathrm{Na}^{+} / \mathrm{I}^{-}$symporter play a role in its $\mathrm{Na}^{+}$dependence and are critical for transport activity. Journal of Biological Chemistry 282 25290-25298.

Wiebe C, Dibattista E \& Fliegel L 2001 Functional role of polar amino acid residues in $\mathrm{Na} / \mathrm{H}$ exchangers. Biochemical Journal 357 1-10.

Wright EM \& Turk E 2004 The sodium/glucose cotransport family SLC5. Pflugers Archiv: European Journal of Physiology 447 510-518.

Zhang EY, Phelps MA, Banerjee A, Khantwal CM, Chang C, Helsper F \& Swaan PW 2004 Topology scanning and putative three-dimensional structure of the extracellular binding domains of the apical sodiumdependent bile acid transporter (SLC10A2). Biochemistry 43 11380-11392.

\section{Received in final form 4 August 2008 \\ Accepted 8 August 2008 \\ Made available online as an Accepted Preprint 15 August 2008}

